\title{
Perspectivas do e-Book acadêmico de acesso aberto ${ }^{i}$
}

\author{
Ursula Blattman \\ Universidade Federal de Santa Catarina, Programa de Pós-graduação em Ciência da Informação, \\ Florianópolis, SC, Brasil \\ ublattmann@gmail.com \\ Juliana Fachin \\ Universidade Federal de Santa Catarina, Programa de Pós-graduação em Ciência da Informação, \\ Florianópolis, SC, Brasil \\ julianafachin@gmail.com \\ Elisabete Werlang \\ Universidade Federal de Santa Catarina, Programa de Pós-graduação em Ciência da Informação, \\ Florianópolis, SC, Brasil \\ betewerlang@gmail.com
}

DOI: https://doi.org/10.26512/rici.v13.n2.2020.21154

Recebido/Recibido/Received: 2019-05-27

Aceitado/Aceptado/Accepted: 2020-04-29

Resumo: Apresenta-se reflexões a respeito das mudanças do livro, do formato impresso para o digital, o e-Book no contexto do acesso aberto, as vantagens e desvantagens do livro no formato eletrônico, ferramentas para autores publicarem seus próprios e-Books, assim como as perspectivas para o futuro da produção e usos do e-Book acadêmico em âmbito internacional. O estudo, de cunho exploratório descritivo, verificou o perfil das bases de dados de e-Books, disponíveis no Portal Capes-Brasil. Entre os resultados, são descritas 50 bases de dados de e-Books disponíveis, classificadas como de acesso aberto ou restrito, país de origem, área de conhecimento e acervo. Para a análise das características e dados quantitativos, foram consultadas as respectivas páginas. Foi possível observar características do acervo de e-Books acadêmicos disponíveis no portal da Capes. A amostra indica a predominância por bases pagas, com acesso restrito, em sua maioria bases comerciais americanas, com acesso limitado apenas à comunidade científica. Esse cenário abre motivações para diversos questionamentos e possíveis pesquisas das mais diversas vertentes. Nesse sentido se fazem necessárias reflexões a respeito do mercado editorial de livros científicos/acadêmicos e suas perspectivas de acesso a toda sociedade.

Palavras-chave: livro eletrônico. modelos de negócios. editoração científica.

\section{Perspectives of the academic open access e-Book}

Abstract: Reflections on changes in the book, from print to digital format, the eBook in the context of open access, the advantages and disadvantages of the book in electronic format, tools for authors to publish their own eBooks, as well as the prospects for the future of international e-Book production and uses. The study was of a descriptive exploratory nature, verified the profile of the eBook databases, available at the Capes-Brazil Portal. Among the results, 50 available eBook databases are described, classified as open or restricted access, country of origin, knowledge area and collection. For the analysis of the characteristics and quantitative data, the respective pages were consulted. It was possible to observe characteristics of the collection of academic eBooks available on the Capes portal. The sample indicates the predominance of paid access, with restricted access, mostly American commercial bases, with limited access only to the scientific community. This scenario opens motivations for various questions and possible research from various aspects. In this sense, it is necessary to reflect on the publishing market of scientific-academic books and their perspectives of access to the whole society.

Keywords: electronic book. business models. scientific publishing. 


\section{Perspectivas del e-Book académico de acceso abierto}

Resumen: Reflexiones sobre los cambios en el libro, desde el formato impreso a la digital, el libro electrónico en el contexto del acceso abierto, las ventajas y desventajas del libro en formato electrónico, las herramientas para que los autores publiquen sus propios libros electrónicos, así como Las perspectivas para el futuro de la producción y usos internacionales de libros electrónicos. El estudio fue de naturaleza descriptiva exploratoria, verificó el perfil de las bases de datos de libros electrónicos, disponibles en el Portal Capes-Brasil. Entre los resultados, se describen 50 bases de datos de libros electrónicos disponibles, clasificadas como de acceso abierto o restringido, país de origen, área de conocimiento y colección. Para el análisis de las características y datos cuantitativos, se consultaron las páginas respectivas. Fue posible observar las características de la colección de libros electrónicos académicos disponibles en el portal de Capes. La muestra indica el predominio del acceso pagado, con acceso restringido, en su mayoría bases comerciales estadounidenses, con acceso limitado solo a la comunidad científica. Este escenario abre motivaciones para varias preguntas y posibles investigaciones desde varios aspectos. En este sentido, es necesario reflexionar sobre el mercado editorial de libros científicos / académicos y sus perspectivas de acceso a toda la sociedad.

Palabras clave: libro electrónico. modelos de negocios. edición científica.

\section{Introdução}

O acesso aberto ao livro eletrônico, conhecido como e-Book, facilita a disseminação, armazenamento, recuperação, acesso e o uso do conhecimento em diversas áreas, indiferente se esse é de conteúdo científico, artístico ou cultural.

O ciclo editorial do e-Book acadêmico segue uma dinâmica diferente da versão impressa, devido à interação entre o leitor, a obra e o autor, possibilitada pelo meio digital. Conforme Bellei (2002) indica, no ambiente digital surge o lautor sendo a convergência presente no mundo da interatividade, da conexão e dos consumidores que, paralelamente, são também produtores de informação. Assim alteram-se os papéis das instituições, conforme aponta Ayris (2014) e Mounier (2018) ao pensar no acesso aberto universal.

A produção de e-Books acadêmicos implica em questões abrangentes, à medida que envolvem vários atores que influenciam no processo de produção, publicação e acesso ao conteúdo digital. Outra questão que norteia esse cenário advém do apoio financeiro por parte das agências de fomento para a pesquisa, políticas nacionais e os interesses das editoras comerciais, ou não, em publicar uma obra e obter lucro com isso.

O autor se depara com algumas escolhas ou imposições ao publicar sua obra. Esse cenário envolve: editoras, órgãos de fomento, instituição de vínculo empregatício do autor ou grupo de pesquisa e, de delimitações dos direitos autorais firmados pelas partes, autor/editor/instituição, estes sujeitos decidem como se dará o acesso ao material publicado. Decidir se permite ou não o acesso aberto ao documento digital dependerá da escolha da editora, que pode ser comercial, pertencer a Instituições de Ensino Superior públicas e ou privadas, de visibilidade nacional ou internacional, seja em comercializar em plataformas ou definir convênios de acesso aberto controlado. 
As possibilidades divergem e, certamente, os editores comerciais visam interesses de publicar e disseminar conteúdos científicos para obter os retornos dos custos envolvidos no processo editorial e de divulgação do material.

Os diferentes mecanismos de adaptação e sobrevivência das universidades, das editoras e dos autores ajustaram-se ao fluxo do processo editorial. Mas para os pesquisadores, o fazer ciência em países como o Brasil, no qual o acesso e uso de conteúdos científicos ainda estão aquém de sistemas de base de dados e assinaturas para bibliotecas universitárias, necessitam de um pensar diferente para que seja possível seguir com o desenvolvimento científico amplo e sustentável para todos.

As mesmas preocupações que atualmente assolam a publicação de e-Books também aplacaram os pesquisadores quando os periódicos científicos passaram a usar o formato digital. Parece uma reprise de duas décadas quando a comunidade científica pensava nos periódicos científicos online, direitos autorais, surgimento do Creative Commons e dos interesses de grandes publicadoras com indicadores. Influência da visibilidade internacional e status quo, no sentido de serem referências na publicação. Oferta ao acesso indiferente, se por convênios na aquisição, acesso e uso de obras individualmente ou no interesse coletivo, como exemplo os acordos CAPES, nas interferências políticas nacionais e no incentivo ao fazer e ao uso de documentos digitais de acesso aberto.

Na obra de Cunha (2016) é possível observar que as diferentes fontes de informação em ciência e tecnologia migram do formato impresso para o formato digital: dicionários, enciclopédias, fontes históricas, manuais, guias, diretórios, revistas, entre outros, e não foi diferente para os livros científicos, do impresso para o eletrônico ou os dois. Considera-se a definição de e-Book proposta por Cunha, a de livro eletrônico, ou, a de livro digital. O e-Book é um suporte informacional disposto na web, encontrado em variados formatos (CUNHA, 2016).

Ao pensar sobre o e-Book acadêmico, estamos novamente nesse imbróglio de onde publicar, em qual formato digital disponibilizar ( $p d f / a$ - portable document format archives; epub - Electronic Publication; odf - open document format; xml - extensible markup language), adotar uma modalidade comercial ou subvencionada (aberto, restrito, pago ou gratuito) e assim por diante. $\mathrm{O}$ universo entorno do e-Book científico é vasto, porque está em processo de adequação às necessidades do seu público consumidor.

Para tanto, o estudo teve como propósito verificar o perfil das bases de e-Books disponíveis no Portal Capes, assim como as perspectivas e tendências para o futuro da produção e usos do e-Book acadêmico em âmbito internacional. 


\section{E-Books no contexto do acesso aberto}

Desde a iniciativa de acesso aberto de Budapest em 2002, a comunicação científica vem mudando o rumo do fazer científico, o movimento ganhou força e adeptos, surgiram as modalidades de sistema aberto - open access, open date, open Science, open book, entre outros. Mas, a mudança cultural não é fácil para a maioria das pessoas, principalmente quando se trata de um modelo de negócios altamente lucrativo no qual poucos se beneficiam.

Os autores Larivière, Haustein e Mongeon (2015, p. 3-9) apresentam um estudo que demonstra que desde 1665 a publicação científica esteve nas mãos das grandes editoras comerciais. No estudo, os autores analisaram as publicações indexadas na Web of Science, entre o período de 1973-2013, e constatam que das editoras comerciais ${ }^{1}$, apenas cinco delas: ReedElsevier, Wiley-Blackwell, Springer, Wolters Kluwer e Taylor \& Francis, dominam mais de 50\% de toda publicação científica, principalmente na área da saúde e ciências naturais.

Estes dados revelam o quanto o negócio editorial científico se tornou um monopólio de publicação, sendo o autor o único que pouco se beneficia deste negócio, e a sociedade tão pouco ainda. Por isso, a comunidade científica aderiu, espontaneamente, ao modelo de publicação em acesso aberto, devido a dois fatores: alto custo na publicação científica e no acesso e visibilidade restrita aos canais formais e onerosos de divulgação.

As editoras trabalham com a perspectiva da realização de negócios, retorno dos investimentos e dos possíveis benefícios; focam na qualidade do conteúdo, na confiabilidade e na credibilidade oriunda do nome da publicadora, do corpo editorial e, paralelamente, da distribuição e acesso do material. Certos elementos do processo editorial vistos na publicação fortalecem a qualidade do conteúdo, pois podem ser validados pelo editor, avaliadores e revisores durante o processo editorial.

Até o século XX a publicação de conteúdos científicos estava, geralmente, vinculada ao formato impresso e produzida pelas editoras comerciais. Porém com a propagação da internet esse modelo vem mudando aos poucos, assim como a comunicação científica no todo. Por exemplo, os eventos presenciais estão incluindo o uso da transmissão instantânea, pelos recursos de armazenamento de conteúdos e webinars. Os artigos em revistas indexados em repositórios institucionais vão além dos indexadores e possíveis motores de buscas; as teses e dissertações estão disponíveis nas instituições de ensino e pesquisa e podem ser acessadas nas

\footnotetext{
${ }^{1}$ As editoras constatadas nos estudos de Larivière, Haustein e Mongeon (2015) foram: American Chemical Society, American Institute of Physics, American Physical Society, Cambridge University Press, Emerald, IEEE, Institute of Physics, Karger, Nature Publishing Group, Optical Society of America, Oxford University Press, Reed-Elsevier, Royal Society of Chemistry, Sage Publications, Springer, Taylor \& Francis, Thieme Publishing Group, Wiley-Blackwell, e Wolters Kluwer.
} 
redes de bibliotecas digitais integradas e assim por diante. A evolução tecnológica permite a convergência de mídias, além disso, a participação instantânea nos diferentes ambientes e recursos oferecidos pela internet.

O estudo de Wick (2011) apresenta as diferenças no ciclo de vida da comunicação científica entre um sistema de publicação em acesso aberto e de um sistema pago. As mudanças ocorrem a partir da cessão dos direitos autorais, sendo no acesso pago exclusivo da editora comercial e se diferenciam principalmente quanto à amplitude do conteúdo científico publicado. Nos moldes do acesso aberto, o conhecimento atinge bibliotecas, escolas, repositórios, bancos e bases de dados, toda Web e em nuvens. A autora explicita que a propagação do conhecimento científico no sistema pago se restringe às bibliotecas e instituições de pesquisa, excluindo a sociedade, porque a ciência é feita de cientistas para cientistas.

Schiltz (2018) enfatiza que o modelo de comunicação científica paga e híbrida devem acabar, pois não é mais aceitável que governos e instituições financiem pesquisas e depois tenham que pagar alto custo pelo acesso. $O$ autor enfatiza também que os serviços editoriais devam ser remunerados, mas com valor justo para os serviços que prestam.

Para que a mudança do sistema pago para o aberto aconteça, várias instituições e áreas de pesquisa estão assumindo o papel de editores, nos quais finalizam e publicam em acesso aberto o conhecimento gerado com suas pesquisas, desvinculando o conteúdo científico das editoras comerciais e ampliando a sua propagação, principalmente, nas redes da internet.

Sempre houve muitas especulações quanto ao modelo e à sobrevivência do acesso aberto no mundo. Para entender esse cenário a Science-Metrix investigou e levantou dados que demonstram na atualidade como está a adesão a esse movimento. A Science-Metrix (2018) ranqueou países e seus modelos de acesso às publicações científicas e técnicas, descobriu que mais da metade do que é publicado no mundo é em acesso aberto. De acordo com os dados do estudo da Science-Metrix, extraídos da Web of Science e na ${ }^{1}$ Science entre 2006 e 2016, o acesso aberto ganhou força internacional e vem crescendo mundo a fora.

O Brasil aparece em 13 lugar na categoria dos que mais publicam, sendo que $74 \%$ de tudo o que é publicado no país está em acesso aberto e irrestrito. Como os dados analisados são oriundos da Web of Science, estima-se que esse número seja superior, haja vista a exclusão de publicações não indexadas nesta base (SCIENCE-METRIX, 2018).

Apesar de inúmeras especulações sobre a manutenção e longevidade dos e-Books, este formato se mantém, um tanto tímido, o Anticipatory Skills for Adapting the Publishing Sector ASAP (2017) estima que o índice de consumo de e-Books no mercado editorial mundial esteja por volta de 7\% de toda produção e a área com maior potencial é a educação. 0 estudo também prevê que, com as mudanças oriundas das tecnologias os e-Books podem alavancar o consumo 
em segmentos definidos, e para isso, indicam a necessidade de estudos que possam mapear qual a necessidade de públicos alvo para cada tipo de material, faixa etária e de serviços informacionais especializados. $\mathrm{O}$ quadro 1 apresenta as vantagens e as desvantagens do livro em formato de e-Book.

Quadro 1 - Vantagens e desvantagens dos e-Books

\begin{tabular}{|c|c|}
\hline Vantagens & Desvantagens \\
\hline $\begin{array}{l}\text { a) Rapidez na produção e distribuição, com } \\
\text { entrega instantânea; } \\
\text { b) Redução de custos ( eliminação de etapas de } \\
\text { produção e comercialização); } \\
\text { c) Economia (ampla disseminação, minimizar } \\
\text { estoques), preços mais baixos; } \\
\text { d) Redução do espaço de armazenamento de } \\
\text { coleções digitais sendo compatível com vários } \\
\text { dispositivos; } \\
\text { e) Preservação do meio ambiente, com a } \\
\text { eliminação do uso do papel; } \\
\text { f) Globalização (vitrine global); } \\
\text { g) Acessibilidade (ampliar tamanho da fonte, } \\
\text { facilitar o acesso e uso); } \\
\text { h) Habilidades multimídia (imagens } \\
\text { tridimensionais com movimentos, sons) e } \\
\text { conectividade com redes sociais; } \\
\text { i) Interesse infantil (contém diversos atrativos } \\
\text { inexistentes nos impressos entre os quais o } \\
\text { som e a imagem em movimento); } \\
\text { J) Possibilidade de hipertexto (assuntos e } \\
\text { autores correlatos), possibilidade de marcaçães } \\
\text { e sincronização; } \\
\text { l) Disseminação da informação de forma rápida } \\
\text { e eficiente (entrega sob demanda, atualização } \\
\text { constante, informação com data de validade, } \\
\text { inclusive manutenção de serviços de alerta } \\
\text { conforme o perfil dos leitores). }\end{array}$ & $\begin{array}{l}\text { a) Barreiras socioculturais (resistência às } \\
\text { mudanças); } \\
\text { b) Expressão cultural e artística sem organização, } \\
\text { tratamento, armazenamento e disseminação } \\
\text { adequada; } \\
\text { c) Requisitos do direito autoral (copyright) e do } \\
\text { Creative Commons (cópias ilegais, divulgação e } \\
\text { armazenamento inadequados); } \\
\text { d) Aspectos dos documentos criados digitalmente } \\
\text { ou digitalizados (diagramação, legibilidade e } \\
\text { acessibilidade do documento digital); } \\
\text { e) Barreiras econômicas para aquisição de } \\
\text { equipamentos (hardware e softwares); } \\
\text { f) Recursos para imprimir (nem todo documento } \\
\text { permite impressão); } \\
\text { g) Barreiras tecnológicas (conexão com a internet, } \\
\text { problemas de velocidade e limites no transporte } \\
\text { de pacotes de informação digital); } \\
\text { h) Dependência tecnológica (hardwares e } \\
\text { softwares adequados e obsoletos - atualização } \\
\text { constante), incerteza da durabilidade; } \\
\text { i) Requisitos de infraestrutura (desde o } \\
\text { planejamento de recarregamento das baterias com } \\
\text { tomadas elétricas, até mesmo fornecimento de } \\
\text { redes remotas WI-FI); } \\
\text { j) Ainda não proporcionam as experiências } \\
\text { sensoriais que o formato físico; } \\
\text { I) Pessoas hiperativas têm mais dificuldade de } \\
\text { concentração com o formato digital. }\end{array}$ \\
\hline
\end{tabular}

Fonte: Adaptado do estudo de Figueiredo (2005, p. 37-40) e ASAP (2017, p. 7-8)

O uso de $e$-Books para a educação com o emprego de recursos informacionais animados, tais como gráficos, figuras, sobreposição de mídias, vídeos e sons podem ajudar em cursos que requeiram foco em teorias e técnicas, recursos considerados aliados para o ensino e a aprendizagem em diferentes níveis educacionais (ASAP, 2017).

Mediante ao exposto, refletimos sobre a importância do acesso aberto e do e-Book acessível a todos, a partir dos impactos que ocorrem nos modos de produção, distribuição, recuperação, acesso e uso pela comunidade científica e a sociedade em geral. Podem-se apontar alterações nos paradigmas do modelo de comunicação científica, devido ao uso das redes sociais 
e acadêmicas no sentido de aproximar usuários, leitores e pesquisadores do conteúdo disponível para o acesso e uso de forma mais dinâmica.

\section{E-Books no contexto internacional}

A publicação de e-Books no mercado editorial internacional segue as tendências das inovações midiáticas. Ao exemplo disso, a Federation of European Publishers-FEP (2018) adverte que as tecnologias estão mudando o rumo das publicações e dos negócios tradicionais. Na União Europeia o modelo de editoração tem aderido às tendências mundiais do setor: mudanças na forma de produção (físico e digital), editoração, design, uso de novos canais de distribuição, agregação de conteúdo, marketing, publicidade e vendas. Conforme o ASAP (2019), as mudanças dos últimos dez anos requerem novas competências para o setor editorial, e, para lidar com essas inovações a federação FEP criou a plataforma MOOC, à qual visa à promoção e capacitação dos profissionais deste mercado, a fim de adequá-los às novas demandas.

O ASAP (2017) realizou um estudo para conhecer as mudanças e efeitos da tecnologia no mercado editorial, em especial, os efeitos dos e-Books, da leitura on-line e dos hábitos dos leitores. A pesquisa mostra que nos EUA e Reino Unido a leitura de $e$-Books atingiu uma margem de $25 \%$. Em específico $28 \%$ da população americana leu um e-Book em 2016. A população francesa ficou na margem de $21 \%$, e os italianos contabilizaram $10 \%$, os alemães $25 \%$ desde 2015. A pesquisa identificou que de 13 a 15\% utilizaram algum dispositivo móvel para realizar a leitura neste formato.

Os dados da pesquisa do ASAP (2017) indicam que dependendo da idade e finalidade da leitura, há diferenças significativas em ambos os formatos: físico e digital. Quando se fala de percepção, fixação de conteúdo, memorização e empatia do formato, são todos elementos impactantes no processo de leitura, satisfação e aprendizado. A pesquisa demonstra que há explícito interesse dos consumidores nos livros digitais e são esses os consumidores que agora ditam as tendências deste mercado, as editoras devem focar em seu nicho de consumidores e disponibilizar novos produtos e serviços direcionados para cada público específico.

Com foco no mercado editorial digital para conteúdos científicos e didáticos, a EBSCO (2019) fez parceria com a plataforma Bookwire, na qual visa a criação, edição e publicação de conteúdos voltados para as tendências do mercado. A parceria entre as empresas alcança um mercado editorial específico: Estados Unidos são quase 10.000 bibliotecas, na América Latina 4.000, sendo mais de 700 apenas no Brasil (BOOKWIRE, 2019).

Kroes Li (2018), diretora de gerenciamento de produtos da EBSCO, divulgou que a empresa está trabalhando com e-Books livres da tecnologia DRM (Digital Rights Management), um gerenciador de direitos autorais para e-Books. Com cerca de 70.000 títulos de 40 editoras, 
esse sistema limita aos usuários certas ações, tais como baixar ou imprimir partes de um texto. Uma forma eficiente de coibir a distribuição não autorizada de seus conteúdos em meio digital.

As limitações de um texto com DRM são definidas pela licença estabelecida no modelo de concessão de acesso ao qual o conteúdo foi vinculado. Isso quer dizer que os e-Books sem DRM poderão ser baixados e impressos sem restrições, caso a assinatura do usuário permita tal uso. Isso não quer dizer que o material é gratuito ou aberto ou que não deve respeitar os direitos autorais, mas que a biblioteca ou o usuário podem adquirir o e-Book e não apenas o acesso ao material (DRM, 2018).

Para permear esse segmento, alguns eventos agrupam especialistas de várias áreas de conhecimento sobre o mercado editorial. O Ebookcraft (2019) é uma conferência realizada desde 2014 pela comunidade produtora de e-Books. O objetivo é reunir especialistas em tecnologia, editoração e design para o debate do uso de tecnologias para a produção de e-Books interativos e inovadores que buscam aplicar no mercado editorial novas experiências advindas da tecnologia. O evento utiliza a plataforma do YouTube, como canal de divulgação para disponibilizar vídeos sobre as edições que já aconteceram.

Em contrapartida ao modelo de negócios pagos existem, duas iniciativas internacionais de plataformas de acesso aberto para e-Books que se destacam: a Internet Archive e a Open Library, ambas oriundas do mesmo projeto do archive.org.

A Internet Archive (2018) disponibiliza, gratuitamente, cerca de 15 milhões de livros e textos para serem baixados, ao todo são 20 milhões de itens. Oferece materiais em diversos formatos, incluindo arquivos Digital Accessible Information System- DAISY. Essa base possui um sistema de empréstimo que possibilita ao usuário acessar o conteúdo on-line ou baixar o livro em seu aparelho eletrônico por um período de duas semanas, gerenciado por um dispositivo de empréstimo digital. A Internet Archive incentiva que a comunidade global contribua com um item físico (livro) para disponibilizar o acesso por meio da plataforma. A própria plataforma já digitalizou cerca de 2,1 milhões de livros e microformas, mas alguns itens podem conter restrições de uso ou reutilização devido aos direitos autorais.

A Open Library (2019) é uma organização sem fins lucrativos, de iniciativa da Internet Archive, conta com um acervo de 20 milhões de registros, são e-Books de diversas áreas do conhecimento. Seu objetivo é disponibilizar para a humanidade a maior quantidade de obras que já foram publicadas, construindo o acesso universal a todo o conhecimento. A plataforma usa um software aberto, com dados abertos e a documentação também está aberta, financiada em parte, pela California State Library e Kahle Austin Foundation.

Outra forma de acesso aos e-Books é por meio dos aplicativos para dispositivos móveisApps, alguns permitem a criação e leitura de e-Books de forma gratuita. A maioria dos Apps de 
leitura disponibilizam uma lista de títulos gratuitos, mas observa-se a frequência de obras de acesso restrito ou a necessidade de pagamento para a coleção completa.

Por exemplo, o Wattpad (2019), um aplicativo gratuito, permite a criação e compartilhamento de e-Books de forma gratuita. Conta com mais de 1.000 publicações e 70 milhões de leitores. Nesse ambiente, o leitor pode se tornar autor e publicar suas histórias assim como receber críticas ou aconselhamentos dos leitores que se interessaram pela postagem. Esse processo, Bellei (2002) denomina lautor, no qual o leitor se transforma em autor. A terminologia surge do neologismo originado na área do marketing, prosumer, do inglês, produtor e consumidor. O visionário Alvim Toffler, utiliza e descreve o termo em sua obra "A terceira onda" considerada a "Era da Informação". Cabe destacar como o avanço das tecnologias de informação e comunicação deixa cada vez mais comum o consumidor transformar-se em produtor e customizar seus próprios produtos de informação.

O mercado internacional tem indicado os rumos que os e-Books estão tomando, bem como as tendências, perfis de usuários, parcerias, investimentos e acima de tudo, a necessidade de inovação para o mercado editorial, ao mesmo tempo em que o setor segue com a produção de livros impressos, também vê-se a oportunidade e a necessidade de investimentos no mercado dos e-Books.

\section{Perspectivas para o futuro do $e-B o o k$}

A empresa Statistia (2019a) fornece uma visão completa do mercado editorial dos vários segmentos, contendo dados setoriais sobre empresas e receitas, às informações sobre produção e consumo de produtos editoriais. As três principais categorias da indústria editorial são livros, jornais e revistas. Os principais números do setor de publicação de e-Books são compilados e disponíveis na plataforma para o acesso pago. As informações são oriundas dos líderes da indústria em publicações e varejo, como: New York Times, Guardian, Gannett, Random House e Barnes and Noblee a Books-A-Million.

Conforme os dados da Statistia (2019c), o volume de vendas de e-Books no mercado consumidor da Alemanha no período de 2010 até 2018 é crescente, pois, dos 1,9 milhões de livros vendidos em 2010 passou para 32,8 milhões dos exemplares vendidos em 2018. Na Alemanha, o preço médio de um e-Book em 2010 era de 10,71 euros, em 2018, o preço médio de um livro eletrônico havia caído para cerca de 6,19 euros (STATISTIA, 2019 b; 2019c). Os dados indicam que a queda do custo é devido ao crescente consumo deste formato de livro.

Conforme Williams (2019), a Bookwire anunciou um crescimento de $65 \%$ nas vendas e, um aumento de $25 \%$ nos títulos registrados para o mercado editorial da Espanha e da América 
Latina. O aumento dos títulos em língua espanhola foi da ordem de 33.000, enquanto os títulos de língua portuguesa subiram $40 \%$, ficando em 32.000 .

Entre as tendências para e-Books no Brasil, Crischley (2019), aponta que em 2017 a Bookwire comprou a plataforma Distribuidora de Livros Digitais (DLD). Como consequência a empresa triplicou suas vendas. No Brasil, o número de títulos distribuídos pela empresa aumentou em cerca de $40 \%$ ao finalizar 2018, com 32.000 títulos. Elena Bazán, gerente da Bookwire no México, atribuiu o crescimento à abertura dos editores para os formatos digitais.

Warner (2011) vai além, faz previsões para livros e tecnologias de e-Books que estarão disponíveis no futuro, ele traça uma linha de tempo na qual descreve cada década e as mudanças no formato dos livros digitais. Segue, abaixo, a visão de mundo e como será as possibilidades dos e-Books, segundo o autor:

- 2020: todos os livros serão multiplataforma e interativos. Os futuros "livros" serão acompanhados de trilhas sonoras, leitmotivs musicais, gráficos em 3-D e streaming de vídeo; - 2030: Todos os livros serão crowdsourced e baseados em nuvem. Os romancistas começarão a projetar seus personagens na forma de conjuntos de figurinhas de vinil. Se isso gerar buzz suficiente, os fãs produzirão o romance de verdade como um wiki;

- 2040: Os autores se tornarão uma espécie de Tamagotchi. "Alimentarão" seus autores favoritos comprando seus livros farão com que seus avatares on-line fiquem menos pálidos e irritantes;

- 2050: A leitura analógica será simulada digitalmente. Mundos virtuais de simulação começarão a incluir "bibliotecas" de esconderijo nas quais você pode se trancar e folhear um livro;

- 2060: Os livros físicos farão um retorno em contextos exasperante. À medida que o material impresso fica mais difícil de obter, o Antiquarian Archipelago se tornará um popular programa de entretenimento informativo, estrelado por arquivistas fortemente armados que se teletransportam de ilha em ilha em busca de joias raras;

- 2070: Todos nós nos tornaremos ciborgues. Novas interfaces cérebro-computador redefinirão a narrativa, à medida que os eletrodos implantados no neocórtex induzem à criação de histórias, sem a intervenção de terceiros, como alucinações sustentadas;

- 2080: Uma Era de Ouro da Fluidez Informacional. Para o benefício dessas pessoas em painéis futuros de publicação - há sempre alguém, por algum motivo, que insiste que não é realmente sobre o texto, mas o cheiro do livro, os livros estarão disponíveis a esta altura, exclusivamente, como linhas de fragrâncias.

A maioria das previsões para a década de 2020 já estão disponíveis no mercado, a exemplo da Rosen Digital (2019), uma empresa visionária que está investindo em e-Books 
educacionais interativos, com conteúdo de áudio, vídeo e imagens, no qual também disponibiliza em sua plataforma vários formatos de conteúdos digitais de diversas áreas de conhecimento, entretanto, todo material é pago.

Lameira (2018) enfatiza que o mercado editorial está mudando, seguindo novas tendências de uso e consumo de produtos editoriais. $\mathrm{O}$ autor lembra que as editoras devem estar nos canais de comunicação onde estão seus leitores, que devem buscar entender as necessidades desses leitores e criar conteúdos interativos, dinâmicos e voltados para uso e acesso via rede, publicações em podcast, tiras, áudio, são cada vez mais frequentes, sobretudo os que versam a questão da acessibilidade e integração de mídias para diversos públicos.

Seguindo esta vertente, as editoras tendem a prestar serviços informacionais focados na experiência de leitura ou obtenção da informação e não apenas na comercialização dos produtos informacionais, segmentando o setor editorial.

A Association of American Publishers - AAP (2019) indica que os editores estão inovando e se adequando ao modelo de negócio para a promoção e comercialização de e-Books no mercado, inclusive formatos integrativos para pessoas com deficiência visual. O objetivo é usar a tecnologia disruptiva para a promoção desse conteúdo em formato digital. Conforme a AAP (2019), várias tendências já são realidade em alguns seguimentos:

a) Uma maneira já disponível é a aplicação de um programa de fidelização, "um Netflix para livros", com acesso à base de dados com grandes números de e-Books e lançamentos, todo conteúdo fica disponível para o acesso, leitura e em alguns casos a impressão;

b) Outra modalidade é o "E-comodato de E-Books", funciona como um empréstimo eletrônico, mas cada editora decide como vai funcionar: pode disponibilizar para apenas um grupo de e-Books e por um período restrito, o acervo pode ser formado por lançamentos ou edições antigas; pode ser lido na tela ou baixado para o dispositivo de leitura; ou limitar a leitura por vezes de acesso ao material; pode trabalhar com pacotes, o leitor paga apenas o que lê; pacotes definidos de títulos em quantidades; em geral o leitor terá opções para escolher;

c) O aluguel do todo ou partes de e-Books também é uma tendência, o leitor pode comprar o acesso por um período de dias pré-estipulado, este formato visa à propagação de $e$ Books científicos, dos quais o pesquisador usa apenas por um período. O mesmo acontece com a impressão por demanda;

d) O uso de recursos e mídias digitais para a promoção dos autores e suas obras, como a criação de "fã-clube on-line de autor"; a promoção de obras por meio de "festivais de histórias on-line". 
Outra tendência é a auto-publicação. O autor pode publicar os seus e-Books de forma gratuita, uma dessas plataformas é a Amazon (2019), na qual o autor pode definir como quer comercializar a sua obra, estipula um valor que achar justo, sem a necessidade de um intermediário neste processo, diferente do formato impresso, em que o editor deliberava em nome do autor.

E-Books oriundos de Recursos Educacionais Abertos "REA" são materiais para ensinar, aprender e pesquisar, que estão em domínio público ou são publicados com licença de propriedade intelectual que permita sua livre utilização, adaptação e distribuição" (UNESCO, 2019). Os REAS permeiam plataformas gratuitas, nas quais, são disponibilizados diversos materiais, todos de acesso aberto. Todo conteúdo considerado REA respeita os direitos autorais, que utiliza a licença Creative Commons de derivação não comercial e compartilhamento igual (CC BY-NC-AS) $)^{2}$. Tem crescido o número de e-Books com derivação de REA para materiais didáticos, principalmente, o que são financiados com dinheiro público. O e-Book didático constitui um mercado que, também, está em ascensão (FEP, 2018).

Em geral, o mercado editorial de e-Books está explorando um novo nicho econômico, a informação contida no e-Book continuará a mesma da impressa (matemática, física, química, entre outros), mas a forma de acesso e interação com essas informações será diferente. Os materiais se constituem com o objetivo de dispor um produto mais atrativo, e principalmente vendável, já que esse sempre foi o trabalho das editoras comerciais. Um ponto positivo neste cenário é que toda inovação vem do mercado, mas se estende para o campo do acesso aberto, principalmente, no que tange a acessibilidade e uso de certas inovações.

Duas estruturas já estão sendo utilizadas pelas editoras e periódicos científicos são elas: Electronic Publication - Epub (utilizado para gerar e-Books), e o MobipocketeBook- Mobi (baseado no padrão Open e-Book, XHTML e JavaScript, que podem ser aplicados em texto, imagens e quadros) ambos aplicados no formato de arquivo. Entretanto, a publicação científica requer outros cuidados e estruturas para indexar, recuperar, rastrear as publicações, citações e usos dos textos eletrônicos na web, quando se fala em acesso aberto, essa não é uma tarefa fácil, pois necessita de estudo e desenvolvimento de tecnologias que possam ser aplicadas para esse fim, sem burlar leis e direitos de autores.

As perspectivas para o futuro dos e-Books estão direcionadas para plataformas de acesso e compartilhamentos em formatos que agreguem conteúdos interativos, integrativos e dinâmicos para os diferentes usuários, desta forma os livros digitais produzidos estão passando por mudanças estruturais e econômicas.

\footnotetext{
${ }^{2}$ Ver mais sobre essa modalidade em: https://creativecommons.org/licenses/by-nc-sa/4.0/deed.pt BR
} 


\section{Método e procedimentos}

A aplicação deste estudo foi de cunho exploratório descritivo (RAMPAZZO, 2013), no qual buscou informações a respeito dos e-Books acadêmicos no mercado editorial internacional e apresentou de forma descritiva as bases de dados que disponibilizam e-Books via o Portal de Periódicos da Capes Brasil.

Para a obtenção dos dados que versam a amostra do estudo, restringiu-se a busca na base do Portal de Periódicos da Coordenação de Aperfeiçoamento de Pessoal de Nível Superior CAPES. A escolha da base se justifica por entender que ela é a responsável pela distribuição do conteúdo científico, considerado fundamental para o ensino superior do Brasil, nos mais diversos campos de conhecimento (CAPES, 2018).

O acesso ao Portal da CAPES, realizado via conteúdo assinado pelas instituições participantes e neste estudo utilizadas as bases de acesso disponibilizadas pela Universidade Federal de Santa Catarina -UFSC. A busca foi realizada por tipologia (em 16 maio 2019), sendo empregados dois campos distintos: 'Livro' e 'Base' (ver imagem 1).

Imagem 1 - Busca por tipologia

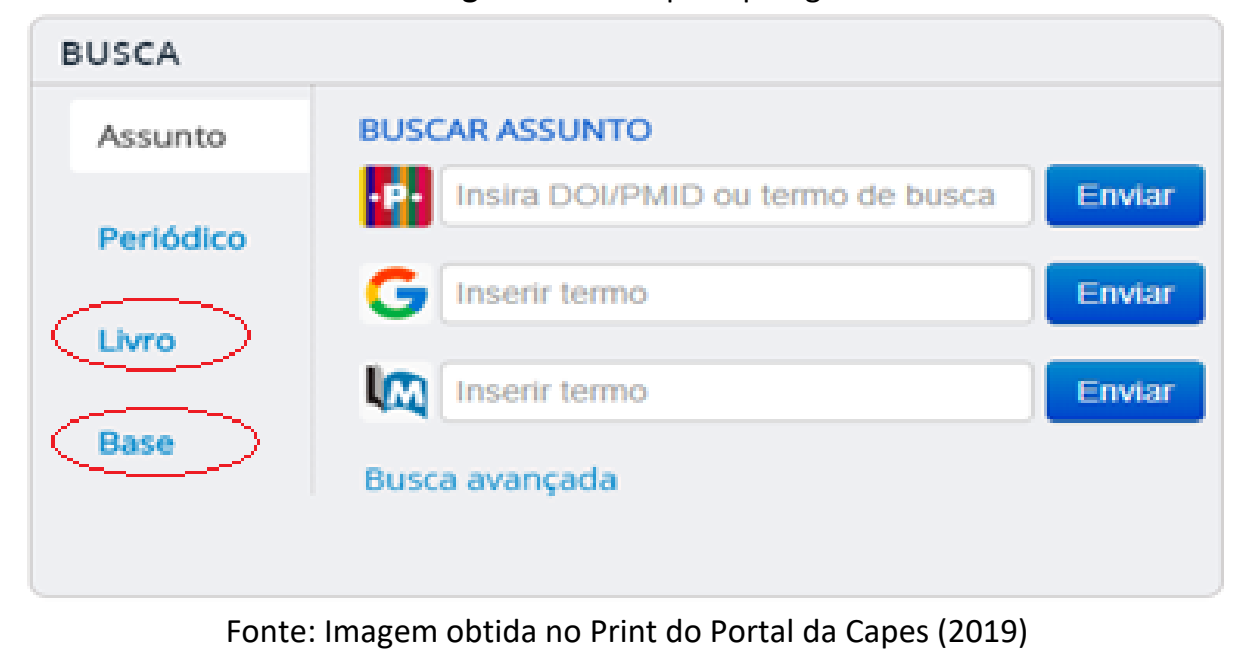

No campo de busca por 'Livro', obteve-se como resultado 13 bases, apresentadas no subcampo 'editor/fornecedor' (ver imagem 2).

Imagem 2 - Busca por Livro 


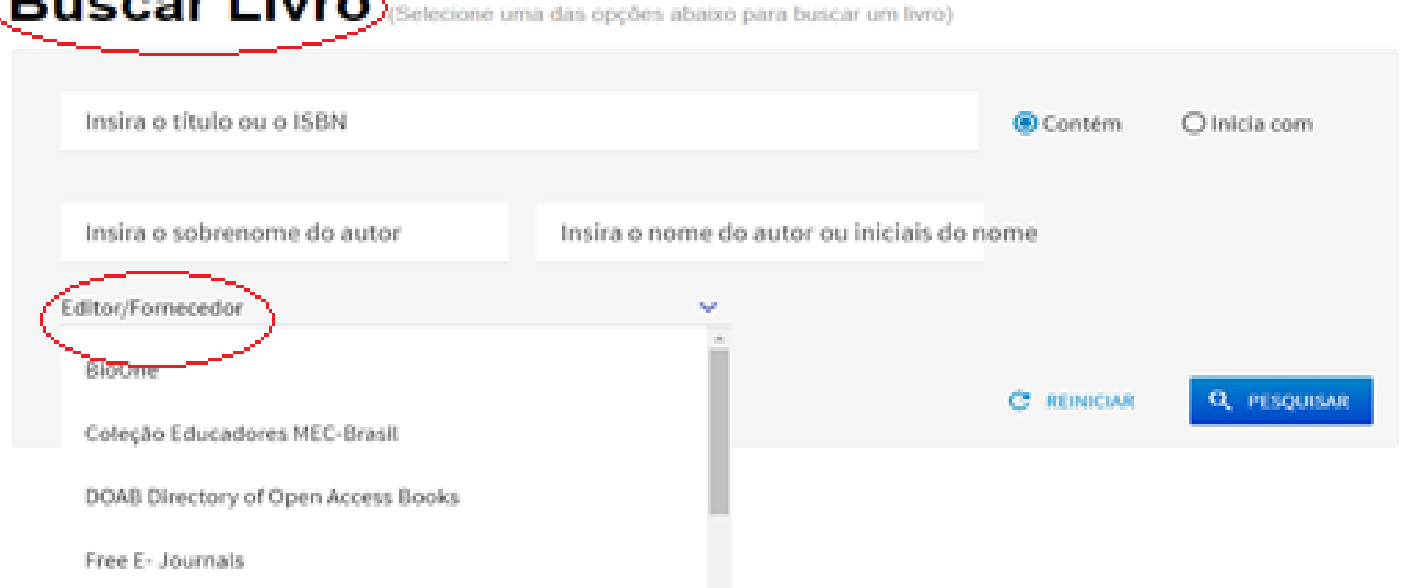

Fonte: Imagem obtida no Print do Portal da Capes (2019)

A segunda busca foi feita em 'base', obtendo uma lista de 39 bases que identificavam seu acervo como 'livro' na tipologia dos materiais (ver imagem 3):

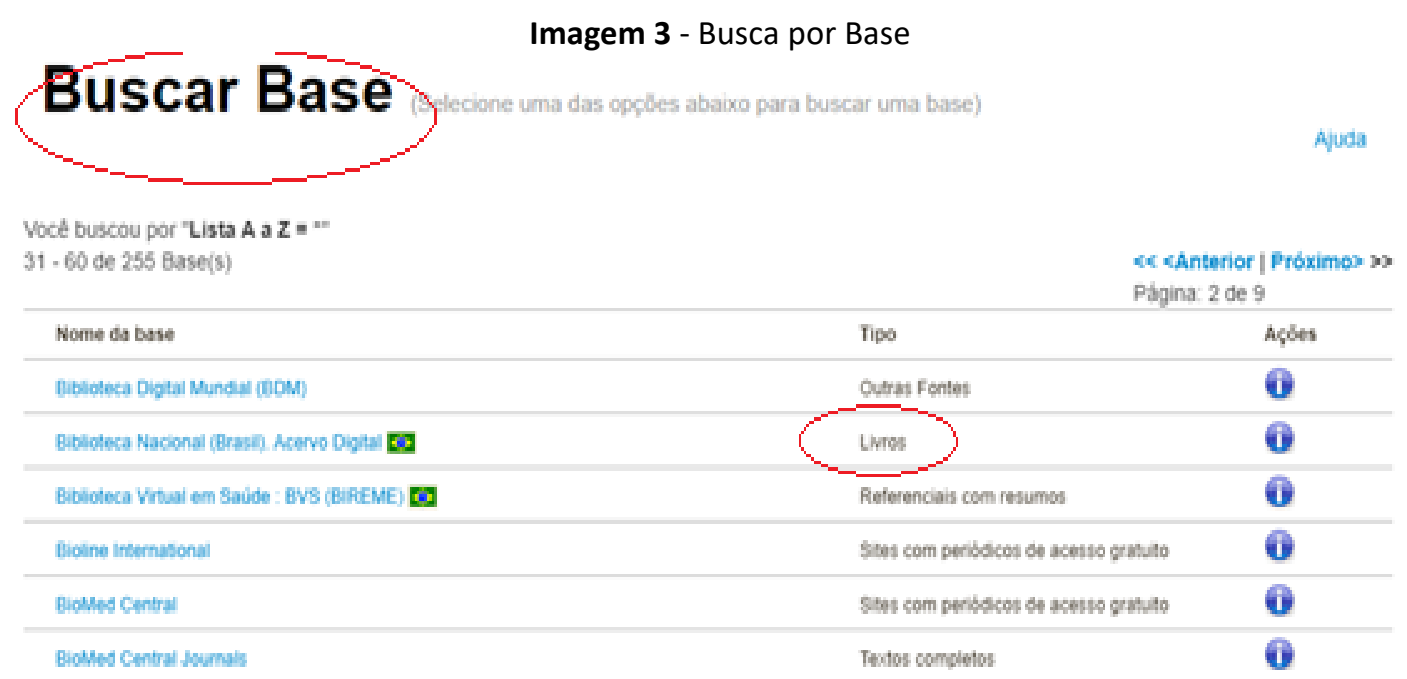

Fonte: Imagem obtida no Print do Portal da Capes (2019)

Ao todo, foram identificadas 52 bases de dados de 'editor/fornecedor' de e-Books, na listagem do Portal de Periódicos da Capes. Salienta-se que, algumas bases aparecem na listagem da busca por livros e também aparecem na listagem de bases, sendo assim, estas foram listadas apenas uma vez.

Das 52 bases obtidas na coleta, foram eliminadas duas da amostra, ficando apenas 50 no total: a PubMed Central, por disponibilizar apenas artigos das edições da revista The British and Foreign Medico-Chirurgical Review, do volume 1 de 1799 ao volume 60 de 1877, e por isso, foi desconsiderada da amostra; e a Free E-Journals, um agregador de conteúdo, identificado em duas bases de publicações científicas em formato de artigos e livros, mas que não foi possível 
obter informações sobre o agregador e o seu acervo, por esse motivo, também não compôs a amostra.

Cabe ressaltar que não foram conferidas base por base para verificar se alguma outra também detinha acervos em formato de e-Books, além das que informavam tal tipologia já que é um critério de busca em campo e subcampo específicos na base da Capes.

Este estudo apresenta a delimitações no sentido de utilizar as bases recuperadas via acesso ao Portal CAPES na Universidade Federal de Santa Catarina e não em outras universidades brasileiras, em função dos tipos de acesso (livre ou por diferentes assinaturas) das IES as bases disponíveis no portal.

Para apresentar os dados, as cinquenta bases foram expostas e classificadas no quadro dois. As bases identificadas como sendo de Acesso Aberto foram discriminadas no corpo do texto, por se tratar de uma descrição mais aprofundada. Para apresentação de suas características e dados quantitativos, foram consultadas as suas respectivas páginas e referenciadas na listagem final do trabalho.

\section{Case: e-Books no Portal Capes do Brasil}

Na pesquisa feita no Portal de Periódicos da CAPES, foram encontradas um total de 255 bases de dados. Verificou-se que, deste total, apenas 50 bases de dados indicam que disponibilizam conteúdo em formato de e-Books.

No quadro 2 foram dispostas as características das 50 bases que compuseram a amostra do estudo. As bases foram classificadas pela forma de acesso: aberto e restrito, país de origem, área de conhecimento e características do acervo que dispunham.

Quadro 2 - Bases de dados de e-Books disponíveis no Portal CAPES

\begin{tabular}{|l|l|l|}
\hline \multicolumn{1}{|c|}{ Base de dados de e-Books } & \multicolumn{1}{c|}{ Descrição } & \multicolumn{1}{c|}{ Áreas } \\
\hline ACM Digital Library & base americana híbrida & Sistemas e computação. \\
\hline Alexander Street Press & base americana & Humanas e Sociais. \\
\hline American Geophysical Union Books & editora americana & $\begin{array}{l}\text { Ciências naturais, terra e } \\
\text { espaço. }\end{array}$ \\
\hline American Psychological Association & base americana & Psicologia. \\
\hline $\begin{array}{l}\text { ASTM Standards and Engineering } \\
\text { Digital Library }\end{array}$ & base americana & \begin{tabular}{l} 
Engenharia. \\
\hline Begell House Digital Library
\end{tabular} \\
\hline BioOne & editora americana & $\begin{array}{l}\text { Engenharia e ciências } \\
\text { biomédicas. }\end{array}$ \\
\hline
\end{tabular}




\begin{tabular}{|c|c|c|}
\hline CINAHL with Full Text (EBSCO) & base americana & Saúde. \\
\hline $\begin{array}{l}\text { Dentistry and Oral Sciences Source - } \\
\text { DOSS (EBSCO) }\end{array}$ & base americana & Saúde e ciências humanas. \\
\hline EBSCOhost & base americana & Todas as áreas. \\
\hline $\begin{array}{l}\text { Eighteenth Century Online - ECCO } \\
\text { (Gale) }\end{array}$ & base americana & Ciências humanas e sociais. \\
\hline Elsevier Science Direct & editora holandesa & Todas as áreas. \\
\hline Galegroup & editora americana & Todas as áreas. \\
\hline IEEE Xplore & base americana & $\begin{array}{l}\text { Engenharia, computação e } \\
\text { tecnologia. }\end{array}$ \\
\hline INTECH Books & base britânica & Todas as áreas. \\
\hline $\begin{array}{l}\text { Instituto Nacional de Estudos e } \\
\text { Pesquisas Educacionais Anísio } \\
\text { Teixeira (Inep) }\end{array}$ & base brasileira & Ciências humanas e educação. \\
\hline McGraw Hill Access & base canadense & Saúde. \\
\hline OAPEN Library & base holandesa & Todas as áreas. \\
\hline OECD library & base internacional & Desenvolvimento econômico. \\
\hline OECD Working Papers. & base internacional & $\begin{array}{l}\text { Ciências humanas, sociais } \\
\text { aplicadas, ciências exatas. }\end{array}$ \\
\hline Optical Society of America & base americana & Ciência da luz- óptica. \\
\hline Portal do Livro Aberto em CT\&I & base brasileira & Todas as áreas. \\
\hline Psyc BOOKS (APA) & base americana & Saúde e ciências humanas. \\
\hline SENAC & editora brasileira & Gestão e tecnologia. \\
\hline SocINDEX with Full Text (EBSCO) & base americana & $\begin{array}{l}\text { Ciências humanas e sociais } \\
\text { aplicadas. }\end{array}$ \\
\hline SPIE Digital Library & base internacional & $\begin{array}{l}\text { Ciência da luz- óptica e } \\
\text { fotônica. }\end{array}$ \\
\hline Springer Book & base suíça & Todas as áreas. \\
\hline SPORT Discus with Full Text (EBSCO) & base americana & $\begin{array}{l}\text { Ciências da saúde, linguística, } \\
\text { letras e artes, biologia. }\end{array}$ \\
\hline $\begin{array}{l}\text { The Making of the Modern World } \\
\text { (Gale) }\end{array}$ & base americana & $\begin{array}{l}\text { Ciências humanas e sociais } \\
\text { aplicadas. }\end{array}$ \\
\hline Wiley Online Library & editora americana & Todas as áreas. \\
\hline \multicolumn{3}{|c|}{ BASES DE ACESSO ABERTO } \\
\hline Acervo Digital & base brasileira & Todas as áreas. \\
\hline Coleção de Educadores MEC-Brasil & $\begin{array}{l}\text { coleção da base } \\
\text { brasileira }\end{array}$ & Todas as áreas. \\
\hline Cultura Acadêmica & base brasileira & $\begin{array}{l}\text { Ciências sociais, humanas e } \\
\text { aplicadas. }\end{array}$ \\
\hline Directory of Open Access Books & diretório holandês & Todas as áreas. \\
\hline Earth and Space Index & base americana & Terra e ciências espaciais. \\
\hline
\end{tabular}




\begin{tabular}{|l|l|l|}
\hline Editora Ministério da Saúde - Livros & base brasileira & Saúde. \\
\hline E-Scholarship & base americana & Todas as áreas. \\
\hline Freebooks4doctors & agregador de bases & Saúde. \\
\hline J-STAGE & $\begin{array}{l}\text { base de periódicos } \\
\text { japonesa }\end{array}$ & $\begin{array}{l}\text { Ciência e tecnologia em } \\
\text { eletrônicos. }\end{array}$ \\
\hline Livros em Português & $\begin{array}{l}\text { agregador de bases } \\
\text { brasileiras }\end{array}$ & Todas as áreas. \\
\hline Miscellaneous Free e-Books & agregador de bases & Todas as áreas. \\
\hline NCBI Bookshef & base americana & Biotecnologia e saúde. \\
\hline Online Books Page & base americana & Todas as áreas. \\
\hline O'Reilly Media & base americana & Computação e sistemas. \\
\hline Open Edition books & base francesa & Humanas e sociais. \\
\hline Open Humanities Press & base britânica & Humanidades. \\
\hline $\begin{array}{l}\text { Project Gutenberg: Fine Literature } \\
\text { Digitally Re-Published }\end{array}$ & base americana & Todas as áreas. \\
\hline Project Muse & base americana & Humanas e sociais. \\
\hline SciELO Livros & base brasileira & Todas as áreas. \\
\hline Springer Link & base suíça & Todas as áreas/ mista. \\
\hline
\end{tabular}

Fonte: Dados da pesquisa (2019)

Das bases verificadas no Portal Capes, que indicavam e-Books em seu acervo, 30 são de acesso restrito aos usuários do portal. Da amostra de 50 bases, 26 são de domínio americano, 7 brasileiras, 3 holandesas, 3 internacionais (sem país definido) e 3 agregadoras de conteúdos, 2 suíças, 2 britânicas, 1 francesa, 1 canadense e 1 japonesa. A concentração maior é de bases americanas, sendo que, seis das 26 são de acesso aberto, mas nem todos os conteúdos são gratuitos, a maioria libera o acesso parcial do seu acervo. Constatou-se que apenas 20 eram de acesso aberto, sendo essas: 17 bases e 3 agregadores de conteúdo, das que indicam que dispõem de e-Books em seu acervo.

Como exemplo de base comercial de acesso pago, temos a Elsevier (2018a), que publica periódicos, livros, conferências, patentes. E a Medline Data, com mais de 15 milhões de publicações de 3.800 periódicos e 37.000 títulos de livros, uma parte desse acervo é de acesso aberto e a outra é paga. Até agosto de 2018 a Elsevier publicou 1.600 títulos de livros em sua plataforma (ELSEVIER, 2018b).

Quanto às bases e editoras que disponibilizam materiais de acesso aberto temos: Acervo Digital, Cultura Acadêmica, Directory of Open Access Books, E-Scholarship, Earth and Space Index, Editora Ministério da Saúde - Livros, J-STAGE, NCBI Bookshef, Online Books Page, O'Reilly Media, NCBI Bookshef, Open Humanities Press, Open Edition books, Project Gutenberg: Fine 
Literature Digitally Re-Published, Project Muse, SciELO Livros, Springer Link. E ainda, a Coleção de Educadores MEC-Brasil e os agregadores Freebooks4doctors, Miscellaneous Free e-Books e Livros em Português. Descrevemos a seguir essas bases, que foram objeto do estudo:

a) Acervo Digital (2019) é um projeto da Biblioteca Nacional do Brasil, conta com cerca de 2.078.154 documentos, imagens e livros digitalizados, disponíveis desde 2015. O projeto tem por finalidade democratizar o acesso aos documentos que compõem o Acervo Memória Nacional por meio da digitalização e disponibilização na página da BNDigital.

b) Coleção de Educadores MEC-Brasil (2018) é uma das coleções do Portal de Domínio Público, conta com 198.119 materiais de diversas tipologias, são 182.448 documentos em texto e 62 livros, que podem ser acessados via Portal CAPES ou Portal do Domínio Público.

c) Cultura Acadêmica (2019) foi criada em 2009 pelo Programa de Publicações Digitais da Propg (Unesp). Conta com cerca de 764 livros nas áreas de Ciências Humanas, Ciências Sociais e Aplicadas e Linguística, Letras e Artes com a produção de docentes, pós-graduandos e pósgraduados brasileiros.

d) DOAB (2018) indica em sua página que disponibiliza cerca de 13.402 livros e capítulos acadêmicos de acesso aberto, revisados por pares, de 282 editoras.

e) Earth and Space Index - AGU (2019) Índice Geofísico sobre o Espaço da Terra -EASI, americano. Iniciou seu acervo em 1988, apresenta cerca de 70.000 registros. As pesquisas podem ser inseridas como linguagem natural ou expressões booleanas. $\mathrm{O}$ acesso é misto, uma parte do acervo é grátis e outra é paga.

f) Editora, Ministério da Saúde - Livros (2019), disponibiliza os livros da área da saúde publicados pela Editora do Ministério da Saúde, desde 1995. A produção estrutura três bases: BVS 164 e-livros, CCS- Centro Cultural da Saúde, Conselho Editorial do Ministério da Saúde.

g) E-Scholarship (2019) Coleção de livros eletrônicos de editoras acadêmicas americanas de todas as áreas de conhecimento. $\mathrm{O}$ acesso integral ao acervo se restringe à comunidade da Universidade da Califórnia, embora uma parte esteja em acesso livre. Conta com 766 livros eBooks que datam de 1982-2004.

h) Freebooks4doctors (2019) é um agregador de bases, criado em 2000 para promover o acesso livre a livros médicos na internet, com acervo em todas as áreas médicas e em vários idiomas. Disponibiliza cerca de 372 livros.

i) J-STAGE - Japan Science and Technology Agency (2018) é uma base japonesa de periódicos da área de tecnologia. Disponibiliza em acesso aberto os resumos da 30ạ Convenção Nacional da Sociedade de Soldagem, em torno de 10 documentos. Não conta em sua página uma modalidade específica para e-Books. 
j) Livros em Português (2019), é um agregador que indexa obras em português de acesso aberto, integra acervos das bases: Portal de Domínio Público, Coleção de Educadores MEC, DOAB, Gale Cengage Virtual Reference Library, Miscellaneous Free e-Books.

I) Miscellaneous Free e-Books (2018) trata-se de um agregador de livros digitais de acesso aberto. Consta no Portal Capes 1.357 livros, oriundos de diversas bases alemãs, britânicas, árabe entre outras.

m) NCBI Bookshelf (2018) é uma base da área da saúde, possibilita a inclusão de materiais por autores, editores e editores participantes. A base foi criada em 2011, desde então conta com o total de 5.848 itens. Sua coleção é de: monografias, obras biográficas, obras coletadas, publicações do governo, manuais, dicionários e enciclopédias, diretrizes, trabalhos estatísticos, relatórios técnicos, livros didáticos, conteúdo da web, literatura cinza, sendo todo o seu material de acesso aberto.

n) Online Books Page (2019) Criada em 1993, conta com uma coleção com mais de 10.000 títulos de livros e textos de acesso gratuito em todas as áreas do conhecimento, em livros são 3 milhões. É uma base da Universidade da Pensilvânia, americana.

o) O'Reilly Media (2019) é uma base americana que iniciou as suas publicações de livros sobre programação e tecnologia de computadores em 1984, com foco em software livre e de código aberto. Em 2001 lança o Safari Books Online um portal que reúne materiais e aprendizado online. A base disponibiliza livros de acesso aberto com publicação de 1989-2011.

p) Open Edition Books (2019) é uma base francesa que publica e-Books de várias editoras, na qual, parte de seu acervo é de acesso aberto e outra é paga. Criada em 2016 pela Open Edition Center, Unidade de Atendimento e Pesquisa-USR, Universidade de Aix-Marseille, EHESS e na Universidade de Avignon. Agrupa acervos da área de humanas e ciências sociais. São aproximadamente 7.122 livros digitais.

q) Open Humanities Press - OHP (2019) é um agregador de conteúdo, criado em 2006 pela organização OHP de autores acadêmicos britânicos, bibliotecas e editoras parceiras. A OHP promove $\mathrm{o}$ acesso aberto a periódicos e livros.

r) Project Gutenberg: Fine Literature Digitally Re-Published (2019) Conta com mais de 59.000 e-Books gratuitos. O Projeto Gutenberg foi fundado em 1971, é a mais antiga biblioteca digital, conta com voluntários que digitalizam, arquivam e distribuem as obras de textos completos e livros de domínio público.

s) Project MUSE (2019) a base foi criada em 1995 pela University Press e a Biblioteca Milton S. Eisenhower da Universidade John Hopkins, a qual iniciou apenas com periódicos, em 2011 passou a publicar e-Books. É uma base da área das ciências da humanidade e sociais. Fornece em seu catálogo uma coleção de e-Books de mais de 125 editoras universitárias e 
comerciais. Reúne um acervo de 57.595 mil livros, sendo que apenas 1.079 são de acesso aberto, 674 periódicos e cerca de 100 obras físicas.

t) Springer Link (2019) é uma base da Springer Nature, que surge da fusão das editoras: Nature Publishing Group (1869), Macmillan Palgrave e Education (1843), Springer Science (1842), S. Fischer (1886) e Business Media. Conta com um acervo de 257.781 em 21 coleções de e-Books, de todas as áreas do conhecimento e em vários idiomas. Mas, apenas uma parte é de acesso aberto e outra é restrita.

u) SciELO Books (2018) oferece um acervo de acesso híbrido de 1.029 títulos, destes, 663 são de acesso aberto, mais 8.801 capítulos em acesso aberto, de um total de 4.547 autores. 0 acervo de e-Books da SciELO são oriundos de editoras universitárias de instituições de ensino superior públicas e de instituições de pesquisas como a FIOCRUZ.

Cabe ressaltar que algumas dessas bases são de acervos mistos, livros, periódicos, imagens, vídeos etc. Quanto ao acesso, nem todas as bases, objeto do estudo, disponibilizam acesso integral ao conteúdo, as bases comerciais (30), disponibilizam acesso a uma parte do seu acervo, outras exigem além da assinatura o pagamento para acesso aos materiais. Para que o usuário tenha acesso ao conteúdo das bases, é necessário entrar via Portal Capes e verificar se a base selecionada permite a concessão de acesso ao material requerido. Apesar de algumas bases disponibilizarem apenas acervos parciais, as bases de acesso aberto demonstram que 0 impacto do movimento open chegou até às obras densas, em formato de livro digital, e em estruturas comerciais com a Springer Nature.

No Brasil o movimento do acesso aberto mostra sua força e maioria, em termos de publicação científica, conforme os dados do Science Metrics (2018). Ao que tange aos e-Books, a amostra revela que a predominância de bases de acesso aberto brasileira são duas: o Portal de Domínio Público e a base SciELO Livros.

Os esforços da comunidade científica, organismos de pesquisa e governamentais, em dispor livros digitais para o acesso livre dos usuários e potenciais usuários, agrega grande valor ao conhecimento científico e para a educação, pois possibilita que pesquisas e estudos aconteçam sem a necessidade de aplicação de grandes recursos financeiros para a obtenção de dados e de conhecimento.

O acesso aos e-Books e demais documentos podem acontecer pela cooperação internacional, como o caso do portal do Portico (2019), um portal de preservação digital de conteúdo científico, que integra acervos de várias bibliotecas e periódicos. O Portico conta com mais de 1.033 bibliotecas, cerca de 2000 associações e associados e 656 editoras de periódicos, acervos de diferentes países, dentre os quais as instituições de ensino superior públicas do 
Brasil. Conforme o relatório da International Association of Scientific, Technical and Medical Publishers-STM (2018, p. 89), é possível acessar no portal, 1.245 .000 e-Books e 200 coleções.

Cabe destacar que, a penetração do e-Book de acesso aberto é lenta se comparada aos periódicos científicos, e isso se dá por duas razões: 1) a questão da digitalização ainda é uma revolução incompleta, porque muitos livros e monografias ainda não estão disponíveis no formato digital; 2) o problema de demanda, no qual as bibliotecas universitárias e acadêmicas necessitam possuir e trabalhar com coleções impressas (STM, 2018, p. 113-114).

No entanto, o relatório (STM, 2018) enfatiza que o e-Book de acesso aberto está em crescimento, mas compõe menos de $1 \%$ das publicações acadêmicas e técnicas. De acordo com as estimativas de 2016, eram cerca de 10 mil títulos. Também cabe salientar o crescimento das editoras comerciais ao publicarem e-Books de acesso aberto. 0 modelo de mercado dominante recebeu o nome de Book Publishing Charges -BPC, e o valor do BPC está em $f 10.000$ (libras) (STM, 2018, p. 114).

Outro exemplo da valoração dos livros para a comunidade científica se dá pela avaliação dos órgãos de fomento e pesquisa, como a CAPES e o sistema de mensuração de impacto, tanto tradicional como alternativo, muito aplicado pelo SciELO Books.

É na convergência de ciência aberta e colaborativa que o e-Book acadêmico tem insurgido, a ampla aplicação deste formato pelas editoras comerciais e científicas demonstra que a tendência deste tipo de publicação, mais densa, tem campo e mercado para a sua aplicação e uso. O exemplo é a apropriação desse nicho por editoras filantrópicas e as comerciais que investem neste mercado em ascensão.

\section{Reflexões antes de alguma possível conclusão}

A comunicação científica é o caminho para o progresso da ciência e da sociedade, mas para que isso aconteça faz-se necessário que conteúdos de qualidade estejam disponíveis em acesso aberto, principalmente, em países com poucos recursos para o ensino e pesquisa, como o caso dos países "em desenvolvimento".

Os livros também possibilitam outras abordagens de categoria reflexiva, criativa e original. Apresentam temas adensados, teorias, ideias e dados, ou até mesmo o autor poderá optar por maneiras diferenciadas para disseminação do conhecimento e produção científica no intuito de alcançar diferentes públicos leitores.

Necessita-se ressaltar as especificidades de cada área, não se trata de estabelecer perfil de publicação ou comunicação das pesquisas científicas, mas sim, de possibilitar a ampliação de canais para a divulgação do saber-fazer-pensar em diversas esferas. 
Cabe destacar que o processo de valoração deste tipo de publicação por órgãos de fomento pode incentivar a sua produção e publicação em acesso aberto, principalmente se o autor obteve recursos financeiros oriundos de agências de fomento públicas, e que foram utilizadas para o desenvolvimento de pesquisa e extensão.

Certamente, o autor busca em seu campo de conhecimento, expor suas ideias e estudos, almeja ser lido, ter reconhecimento profissional e pessoal. Se sua obra estiver disponível em acesso aberto, ampliará os canais de comunicação, os formais e os informais, como as redes sociais, gerando visibilidade e maior amplitude de leituras e usos deste tipo de conteúdo.

Mas não é essa a realidade das publicações deste formato, pois a amostra do estudo indicou que a predominância do acervo do Portal de Periódicos da Capes é composta por bases pagas, em sua maioria bases comerciais americanas, com acesso limitado apenas à comunidade científica. O fazer científico ainda carece de reflexões sobre o modelo de acesso.

No entanto, cabe à comunidade científica discutir e estudar aspectos sobre acesso, usos e impactos dos e-Books acadêmicos para desvelar esse cenário informacional. É crucial a necessidade de estabelecer políticas para as diferentes coleções de e-Books tais como a Coleção SciELO tem desenvolvido em sua base.

\section{Referências}

AMAZON. Publique você mesmo e- Books e livros com capa comum sem pagar nada com o Kindle Direct Publishing e alcance milhões de leitores na Amazon. Homepage, [S.I.], 2019. Disponível em: https://kdp.amazon.com/pt BR?ref =kdpgp p br psg kw ad48 Acesso em: 6 fev. 2019.

ARCHIVE.ORG. Sobre. Homepage, [S.I.], 2019. Disponível em: https://archive.org/ Acesso em: 19 fev. 2019.

ASAP. Plataforma MOOC. Homepage, [S.I.], 2019. Disponível em: http://www.erasmusasap.eu/mooc-platform/ Acesso em: 11 fev. 2019.

ASAP. Anticipatory Skills for Adapting the Publishing Sector. Federation of European Publishers: ASAP, [S.I.], 2017. Disponível em: http://www.erasmus-asap.eu/wpcontent/uploads/2017/06/R2 2 Analysis digital books.pdf Acesso em: $11 \mathrm{fev} .2019$. ASSOCIATION OF AMERICAN PUBLISHERS. Innovative ways to deliver books and journals. Publishers.org, Washington, 2019. Disponível em: https://publishers.org/prioritiespositions/expanding-consumer-choice\#1 Acesso em: 19 fev. 2019.

AYRIS, Paul. Open access e-Books: the role of the institution. Insights, Witney, Reino Unido, v. 27, p. 7-10, 2014.

BELLEI, Sérgio Luiz Prado. O livro, a literatura e o computador. São Paulo: Educ/UFSC, 2002. 
BIBLIOTECA NACIONAL. Acervo digital. Biblioteca Nacional, Rio de Janeiro, 2019. Disponível em: http://bndigital.bn.gov.br/ Acesso em: 17 fev. 2019.

BOOKWIRE. Sobre. Homepage, [S.I.], 2019. Disponível em: http://br.bookwire.net/Acesso em: 7 fev. 2019.

BRASIL. MINISTÉRIO DA SAÚDE. Editora do Ministério da Saúde. Brasília, 2019. Disponível em: http://editora.saude.gov.br/livros/ Acesso em: 19 fev. 2019.

COORDENAÇÃO DE APERFEIÇOAMENTO DE PESSOAL DE NÍVEL SUPERIOR. Histórico do portal de periódicos. Homepage, [S.I.], 2018. Disponível em: http://www-periodicos-capes-govbr.ez46.periodicos.capes.gov.br/index.php?option=com pcontent\&view=pcontent\&alias=hist orico\&Itemid=124 Acesso em: 11 mar. 2019.

COORDENAÇÃO DE APERFEIÇOAMENTO DE PESSOAL DE NÍVEL SUPERIOR - CAPES. Livros em Português. Homepage, [S.I.], 2019. Disponível em: http://www-periodicos-capes-gov-br Acesso em: 8 mar. 2019.

COORDENAÇÃO DE APERFEIÇOAMENTO DE PESSOAL DE NÍVEL SUPERIOR - CAPES.

Miscellaneous Free e-Books. Homepage, [S.I.], 2019. Disponível em: http://www-periodicoscapes-gov-br Acesso em: 8 mar. 2019.

CULTURA ACADEMICA. Sobre. São Paulo: Unesp, 2019. Disponível em: http://www.culturaacademica.com.br/sobre/ Acesso em: 9 fev. 2019.

CUNHA, Murilo Bastos. Para saber mais: fonte de informação em ciência e tecnologia. 2. ed. Brasília: Briquet de Lemos, 2016.

DIGITAL RIGHTS MANAGEMENT (DRM). Wikipedia.org, jan., 2017. Disponível em: https://en.wikipedia.org/wiki/Digital rights management Acesso em: 9 fev. 2019.

DIRECTORY OF OPEN ACCESS BOOKS - DOAB. Requisitos para participação dos editores. Homepage, [S.I.], 2018. Disponível em:

https://www.doabooks.org/doab?func=forPublishers\&uiLanguage=en Acesso em: 9 fev. 2019.

DOMÍNIO PÚBLICO. Sobre. Homepage, [S.I.], 2019. Disponível em:

http://www.dominiopublico.gov.br/Missao/Missao.jsp Acesso em: 6 fev. 2019.

EARTH AND SPACE INDEX -AGU. Sobre. Homepage, [S.I.], 2019. Disponível em:

https://agupubs.onlinelibrary. wiley.com/search/advanced?view=search\&adv=1 Acesso em: 6 fev. 2019.

EBOOKCRAFT. Sobre. Tech Forum, Canadá, 2019. Disponível em:

http://techforum.booknetcanada.ca/ebookcraft/ Acesso em: 11 fev. 2019.

EBOOKCRAFT. Canal YouTube. BookNet_Canada, Canadá, 2019. Disponível em:

https://www.youtube.com/channel/UCv62canXJChXqjegPv9H9-A Acesso em: 21 fev. 2019.

EBSCO. Sobre. Homepage, [S.I.], 2019. Disponível em: https://www.ebsco.com/ Acesso em: 7 fev. 2019. 
ELSEVIER. Books. Homepage, [S.I.], 2018a. Disponível em:

https://www.elsevier.com/solutions/sciencedirect/content Acesso em: 5 fev. 2019.

ELSEVIER. eBook titles: Frontlist for. Homepage, [S.I.], 2018b. Disponível em: https://www.elsevier.com/solutions/sciencedirect/content/book-title-lists Acesso em: 5 fev. 2019.

E-SCHOLARSHIP. Sobre. UC Press E-Books Collection, California, 2019. Disponível em: https://publishing.cdlib.org/ucpressebooks/search?sort=title\&relation=escholarship.cdlib.org \&style=eschol\&rights=Public Acesso em: 2 fev. 2019.

FEDERAÇÃO DE EDITORES EUROPEU-FEP. Anticipatory Skills for Adapting the Publishing Sector (ASAP). FEP, [S.I.], 2019. Disponível em: https://fep-fee.eu/ANTICIPATORY-SKILLS-FORADAPTING Acesso em: 11 mar. 2019.

FIGUEIREDO, Andressa Balbi. O livro na era digital: o impacto das novas tecnologias no mercado editorial brasileiro. 2005. 49 f. Trabalho de Conclusão de Curso (Graduação em Comunicação) - Escola de Comunicação, Universidade Federal do Rio de Janeiro, RJ, 2005.

FUNDAÇÃO INSTITUTO DE PESQUISAS ECONÔMICAS. Desempenho real do mercado livreiro 2006-2017: Científicos, Técnicos e Profissionais. São Paulo: CBL: SNEL: FIPE, 2017. Disponível em: http://pesquisaeditoras.fipe.org.br/Home/Relatorio/3 Acesso em: 6 out. 2018.

FREEBOOKS4DOCTORS. Sobre. Homepage, [S.I.], 2019. Disponível em: http://www.freebooks4doctors.com/f.php?f=about Acesso em: 3 fev. 2019.

INTERNATIONAL ASSOCIATION OF SCIENTIFIC, TECHNICAL AND MEDICAL PUBLISHERS - STM. The STM Report: an overview of scientific and scholarly publishing. Netherlands: International Association of Scientific, Technical and Medical Publishers, 2018. Disponível em: https://www.stm-assoc.org/2018 10 04 STM Report 2018.pdf Acesso em: 14 fev. 2019.

INTERNET ARCHIVE. eBooks e textos. Homepage, [S.I.], 2019. Disponível em: https://archive.org/details/texts\&tab=about Acesso em: 14 fev. 2019.

KROES LI, Kara. Removing Barriers to Access: DRM-free EBSCO eBooks Improve Access for Users. Library Resources: EBSCO, [on-line], 26 mar. 2018. Disponível em: https://www.ebsco.com/blog/article/drm-free-ebsco-ebooks-expand-user-research-andlibrarian-choice Acesso em: 11 fev. 2019.

LAMEIRA, Daniel. O ponto cego do mercado editorial. Publishnews, São Paulo. 26 nov. 2018. Disponível em: https://www.publishnews.com.br/materias/2018/11/26/o-ponto-cego-domercado-editorial Acesso em: 14 fev. 2019.

LARIVIÈRE, Vicent; HAUSTEIN, Stefanie; MONGEON, Philippe. The Oligopoly of Academic Publishers in the Digital Era. PLoS ONE, [on-line], v. 10, n. 6, p. 0127502, 2015.

MOUNIER, Pierre. Em direção ao acesso aberto universal? Por que precisamos de bibliodiversidade em vez de uma "bala de prata". SciELO em Perspectiva, [on-line], 14 ago. 2018. Disponível em: https://blog.scielo.org/blog/2018/08/14/em-direcao-ao-acesso-abertouniversal-por-que-precisamos-de-bibliodiversidade-em-vez-de-uma-bala-de-prata/ Acesso em: 4 set. 2018. 
NCBI BOOKSHELF. Sobre. Homepage, [S.I.], 2018. Disponível em:

https://www.ncbi.nlm.nih.gov/books/NBK51661/Acesso em: 4 set. 2018.

OPEN ACCESS PUBLISHING EUROPEAN NETWORKS - OAPEN. About. Homepage, [S.I.], 2018.

Disponivel em: http://www.oapen.org/home Acesso em: 4 set. 2018.

ONLINE BOOKS PAGE. Sobre. Homepage, [S.I.], 2019. Disponível em:

http://onlinebooks.library.upenn.edu. Acesso em: 11 fev. 2019.

OPEN EDITION BOOKS. Sobre. Homepage, [S.I.], 2019. Disponível em:

https://books.openedition.org/bibpompidou/1024 Acesso em: 9 fev. 2019.

OPEN HUMANITIES PRESS. Sobre. Homepage, [S.I.], 2019. Disponível em:

http://www.openhumanitiespress.org/about/community/Acesso em: 9 fev. 2019.

OPEN LIBRARY. About. Homepage, [S.I.], 2019. Disponível em:

https://openlibrary.org/about/vision Acesso em: 11 fev. 2019.

O'REILLY MEDIA. About. Homepage, [S.I.], 2019. Disponível em:

https://www.oreilly.com/about/ Acesso em: 11 fev. 2019.

PORTAL DOMÍNIO PÚBLICO. Coleção Educadores. Homepage, [S.I.], 2018. Disponível em: http://www.dominiopublico.gov.br.Acesso em: 5 set. 2018.

PORTICO. Sobre. Homepage, [S.I.], 2019. Disponível em:

https://www.portico.org/coverage/libraries Acesso em: 8 fev. 2019.

PROJECT MUSE. Sobre. Homepage, Baltimore, 2019. Disponível em:

https://about.muse.jhu.edu/about/story/ Acesso em: 9 fev. 2019.

PROJECT GUTENBERG: FINE LITERATURE DIGITALLY RE-PUBLISHED. Sobre. Homepage, [S.I.], 2019. Disponível em: http://www.gutenberg.org/wiki/Main Page Acesso em: 08 fev. 2019.

RAMPAZZO, Lino. Metodologia científica: para alunos dos cursos de graduação e pósgraduação. 7. ed. São Paulo: Loyola, 2013. 154 p.

ROSEN DIGITAL. Sobre. Homepage, [S.I.], 2019. Disponível em: http://www.rosendigital.com/ Acesso em: 11 fev. 2019.

SCHILTZ, Marc. Science without publication paywalls: cOAlition S for the realization of full and immediate Open Access. PLoSBiology, [on-line], v. 16, n.9, p. e3000031, 2018.

STATISTA. Books \& Publishing: Statistics and market data on Books \& Publishing. Homepage, [S.I.], 2019a. Disponível em: https://www.statista.com/markets/417/topic/477/bookspublishing/Acesso em: 4 abr. 2019.

STATISTA. Sales volume of e-Books on the consumer market in Germany from 2010 to 2018 (in million copies). Homepage, [S.I.], 2019b. Disponível em: https://www.statista.com/statistics/385750/e-book -market-key-figures-germany/_Acesso em: 4 abr. 2019. 
STATISTA. Average e-Book price in Germany from 2010 to 2018 (in euros). Homepage, [S.I.], 2019c. Disponível em: https://www.statista.com/statistics/385768/e-book s-average-pricegermany._Acesso em: 4 abr. 2019.

SCIELO LIVROS. Sobre. Homepage, São Paulo, 2018. Disponível em: http://books.scielo.org/ Acesso em: 19 fev. 2019.

SCIENCE METRIX. Analytical support for Bibliometrics indicators: open access availability scientific publications. Montreal, Canadá, jan. 2018. Disponível em: http://www.sciencemetrix.com/sites/default/files/science-metrix/publications/sciencemetrix open access availability scientific publications report.pdf Acesso em: 19 fev. 2019.

SPRINGER LINK. About. Homepage, [S.I.], 2019. Disponível em:

https://group.springernature.com/gp/group/aboutus/our-history Acesso em: 19 fev. 2019.

TOFFLER, Alvin. A terceira onda. Rio de Janeiro: Record, 1980.

UNESCO. Recursos Educacionais Abertos - REA. Homepage, [S.I.], 2019. Disponível em: http://www.unesco.org/new/pt/brasilia/communication-and-information/digitaltransformation-and-innovation/ict-in-education/open-educational-resources/Acesso em: 8 fev. 2019.

WARNER, James. O futuro dos livros. McSweeney's, São Francisco, 24 mar. 2011. Disponível em: https://www.mcsweeneys.net/articles/the-future-of-books Acesso em: 8 fev. 2019.

WATTPAD. Sobre. Homepage, [S.I.], 2019. Disponível em: https://www.wattpad.com/Acesso em: 11 fev. 2019.

WICK, Nancy. UW Libraries hosts exhibit on open access scholarly publishing. UW News, University of Washington, 19 out. 2011. Disponível em:

http://www.washington.edu/news/2011/10/19/uw-libraries-hosts-exhibit-on-open-accessscholarly-publishing/ Acesso em: 4 abr. 2019.

WILLIAMS, Mark. Bookwire sees 65\% ebook sales growth in Ibero-America in 2018. Moves into audiobooks. The New Publishing Standard, 05 Feb., 2019. Disponível em:

https://thenewpublishingstandard.com/bookwire-sees-65-ebook-sales-growth-ibero-america2018-moves-audiobooks/Acesso em: 4 abr. 2019.

'Texto ampliado oriundo da versão compactada publicada no SciELO 20 anos. Ver em: BLATTMANN, Ursula; FACHIN, Juliana; WERLANG, Elisabete. Acesso aberto ao e-Book acadêmico. PreprintsSciELO 20 Anos: GT - Relevância dos livros acadêmicos na comunicação da pesquisa, 1 out. 2018. Disponível em: http://preprints.scielo.org/documents/article/view/127/91 